\title{
Harvey Siegel \\ New Work on Critical Thinking: Comments on Frímannsson, Holma and Ritola
}

I am grateful to Guðmundur Frímannsson, Katariina Holma and Juho Ritola for their close attention to my work and for developing it in valuable new directions. It is gratifying that, to varying degrees, all three embrace and build on the 'reasons conception' of critical thinking developed in Educating Reason ${ }^{1}$ and subsequent publications. I am fortunate not to have to defend myself from their criticisms, for there are few if any in these papers. ${ }^{2}$ Instead I focus here on the new ground they cultivate. Each makes important contributions, detailed next.

Frímannsson's 'Reasons and Normativity in Critical thinking' rightly notes the fundamental normative character of critical thinking, and offers a rich philosophical account of that normativity and its manifestation in the central role that reasons play in both the theory and practice of critical thinking. He connects his analysis both to key figures (Plato, Aristotle, Kant) in the history of Western philosophy and to important authors in contemporary discussions (Parfit, Broome, Skorupski, Scanlon, etc.). As Frímannsson's discussion makes clear, for these latter writers the notion of reasons is central to their philosophical efforts; their theories of reasons/rationality/normativity are complex and wide-ranging, crossing conventional boundaries between epistemology, ethics, action theory and other sub-areas of philosophy. Like Holma, Frímannsson emphasizes the character of the critical thinker and the psychological barriers that must be overcome in order to cultivate that character in students. He quite correctly notes the somewhat limited reach of my own account of reasons and instructively enlarges that account by utilizing Skorupski's analysis of reasons relations. While I cannot commit myself to all the details of Skorupski's account, I wholeheartedly embrace his views that reasons are normatively basic and cannot be reduced either to natural facts or to supervenience relations, and that there is a tight conceptual connection between reasons, rationality and normativity. My own view, that reasons are

1 H. Siegel, Educating Reason: Rationality, Critical Thinking, and Education (New York: Routledge, 1988).

2 This is of course compatible with their being excellent manifestations of critical thinking, since critical thinking needn't be critical in the sense of being negative. Cf. H. Siegel, 'Must Thinking Be Critical to Be Critical Thinking?', Philosophy of the Social Sciences 20.4: 453-461 (1991).

Harvey Siegel, University of Miami, USA

E-mail: hsiegel@miami.edu

Studier i Pcedagogisk Filosofi | www.ojs.statsbiblioteket.dk/index.php/spf | ISSN nr. 22449140

Årgang 4 | Nr. 1 | 2015 | side 55-62 
considerations that purport to support the items (beliefs, claims, propositions, judgments, actions, etc.) for which they are reasons - and that good reasons are those that actually do so support those items - seems to me, as it seems to Frímannsson, to be quite in the spirit of Skorupski's account. ${ }^{3}$ This notion of reasons corresponds to Broome's pro tanto reasons: "things that count in favour of...or against" believing something or acting in some particular way, as Frímannsson puts it.

Frímannsson is right, I think, both to accept Broome's claim that rationality is not a matter of "responding correctly to reasons" (among other reasons, because sometimes we can reasonably disagree, with neither of us responding incorrectly to reasons ${ }^{4}$ ) and to deny that this claim, concerning what rationality is not, requires the rejection of the view, defended by both Frimannsson and me, that rationality is a matter of being appropriately moved by reasons. This 'appropriate movement', on my view, has two parts that correspond to the two components of critical thinking, the reason assessment component and the critical spirit component. These in turn correspond to two features of reasons: their probative force - the degree to which they in fact support the things for which they are reasons - and their normative impact - the degree to which they actually move us to believe, judge and/or act in ways that reflect that probative force. One is appropriately moved by reasons when one believes, judges and acts in accordance with the probative or evidential force of those reasons - that is, one assesses the probative force of those reasons well. One is appropriately moved by reasons when one believes, judges or acts on the basis of one's appreciation of that normative force - that is, one believes, judges and acts as one does because one recognizes that the reasons in play support that belief, judgment or action to the degree that they in fact do; the assessment of the probative strength of the reasons guides the belief, judgment or action in question. ${ }^{5}$ Frímannsson's discussion faithfully reflects these features of my view, and builds on them insightfully. His rejection of an analysis of 'being appropriately moved by reasons' in terms of desires is insightful, as is his positive account of it in terms of both rational assessment and the character traits constitutive of the critical spirit. His insistence on the central role of education in developing both the skills and the character of the critical thinker is welcome. I am grateful for his philosophically rich and sympathetic discussion.

Holma's 'The Critical Spirit: Emotional and Moral Dimensions of Critical Thinking' offers an important refinement and deepening of the notion of the critical spirit, the notion most underdeveloped in my account. I welcome her insistence that that spirit includes both emotional and moral dimensions. She quite rightly notes the popularity in educational

3 H. Siegel, 'The Role of Reasons in Moral Education', in D.J. deRuyter and S. Meidema, eds., Moral Education and Development: A Lifetime Commitment (Festschrift for Jan Steutel), Rotterdam: Sense Publishers, 2011, pp. 59-69.

4 H. Siegel, 'Argumentation and the Epistemology of Disagreement', Cogency (2013) 5.1: 135-170.

5 H. Siegel, Rationality Redeemed?: Further Dialogues on an Educational Ideal (London: Routledge, 1997), pp. 49-51. 
policy circles of a 'skills only' view of critical thinking, and effectively argues that this view, which ignores the critical spirit component, will not do.

Consider, first, the place of emotions in critical thinking. Holma rightly rejects a sharp emotion/reason dichotomy, noting, as has Scheffler, ${ }^{6}$ that emotions play important roles in cognition: as she puts it, they "work in cooperation with cognition in the processes of interpreting the world." They also play an important role in the strengthening of moral agency, a fact that "has enormous educational significance." Most importantly, they play a crucial role in motivating critical thinking, a central dimension of the critical spirit.

Consider next the moral dimensions of critical thinking. Holma rightly insists that education centrally involves the formation of persons and so is inevitably morally charged, and so that educational aims cannot be morally neutral. The reasons conception of critical thinking involves the moral principle of respect for persons - on my account, that principle justifies the ideal, since any other sort of education which did not aim to foster students' critical thinking would fail to treat them with respect ${ }^{7}$-- and is in that respect at least a moral component of the ideal.

Holma urges that the ideal of critical thinking "presupposes the epistemic value of truth", and that the commitment to the ideal of truth "also has a moral dimension." She is right that the commitment has a moral dimension, but this should be distinguished from the claim that truth itself has such a dimension. Holma is certainly right that sometimes we are morally obliged to seek the truth, even though it would be easier for us not to do so. And she is right to insist that "[t]he commitment to the ideal of truth...has a moral dimension", and that " $t]$ he decision to investigate...exemplifies the moral nature of the pursuit of truth." (my emphases) But this doesn't establish that the value of truth is itself moral rather than epistemic. And it doesn't rule out the possibility of pursuing the truth for immoral ends. Rather, it is these commitments and decisions that are the proper locus of morality. I am not sure whether this is a substantive difference between us; I hope not. We are agreed about the moral character of the commitments and decisions. ${ }^{8}$

6 I. Scheffler, In Praise of the Cognitive Emotions and Other Essays in the Philosophy of Education (New York: Routledge, 1991); cf. Siegel, Educating Reason, ch. 2.

7 Holma thus understates the case when she says that "the educational ideal of critical thinking is compatible with the moral requirement of respect for persons." On my view, the ideal is not just compatible with the moral principle; it is required by it, since no other educational agenda honors that principle. The principle of respect for persons is not the only justification offered for the ideal, but it is the most fundamental. Cf. Siegel, Educating Reason, chapter 3.

8 Holma's very brief remarks on the "semantic account of truth" might be clearer. What is it for a true sentence, description or theory to "hold up"? She endeavors to avoid a correspondence theory (without so naming it), in my view unnecessarily. She is right that "the concept of critical thinking is fundamentally linked to the concept of truth"; this linkage is I think rather straightforward: critical thinking involves competently assessing the probative force of reasons, such reasons constitute or supply reasons for belief, and believing that $p$ just is believing that $p$ is true. On the correspondence theory I recommend Alvin Goldman's admirably clear discussion and defense in chapter two of his Knowledge in a Social World (Oxford, 1999); for discussion see my essay review of Goldman's book, Argumentation (2002) 16.3: 369-382, and my 'Knowledge, Truth and Education', in D. Carr, ed., Education, Knowledge, and Truth: Beyond the Postmodern Impasse, London: Routledge, 1998, pp. 19-36. 
Holma urges that "this moral ideal [of respect for persons] should be presented to students as a criterion of thinking critically on moral and political issues." This may be right, but it needs to be handled carefully. It is not a criterion in the sense that epistemic criteria - those that determine the quality of candidate reasons - are criteria of critical thinking.' However, the principle of respect for persons can function as a criterion determining the quality of thinking and arguments concerning moral and political matters, insofar as it is itself established as strongly justified on the basis of the epistemic criteria just mentioned. I agree with Holma that it is so justified, and so may rightly be considered a criterion in this sense in the moral/political domain.

However, while we agree that the principle enjoys that justificatory status, we apparently do not agree on what affords it that status. Holma rests her case for the principle on "two crucial insights of philosophical pragmatism": Peirce's fallibilism and Goodman's 'initial credibility.' We are agreed concerning fallibilism, although Holma understands that doctrine - that human knowledge ${ }^{10}$ is essentially uncertain and always open to revision to involve also the claim that although uncertain and revisable, "the bodies of knowledge we now have...have...survived the process of evolution to this point; as such, they provide the best available starting point for how to proceed at the present moment with respect to further inquiry." This claim about current beliefs ("bodies of knowledge we now have") being "the best available starting point" (my emphasis) is not well understood as a part or implication of fallibilism; it is a further, independent pragmatist thesis. In fact it is very like (if not identical to) Goodman's thesis concerning initial credibility: as Holma puts it, speaking for both Peirce and Goodman, "we have to begin our thinking, doubting and criticizing from where we are and thus start the refinement of our thinking from our current conceptions. Our current conceptions have some initial credibility, because they have been formulated during the generations in interaction with a surrounding world as well as other people."

I agree with Holma that the difference between this view and an "all-embracing Cartesian doubt is clear: in cases where we have no serious alternatives to our current beliefs,

9 For example, a candidate reason that begs the question is not a good reason, while one that enhances the rational believability of its object is a good reason. Epistemic criteria like these determine what counts as a good reason. The principle of respect for persons is not a criterion of this sort. I have discussed such criteria in many places, from Educating Reason on. There is a close connection between something's being a good reason and its role in a good argument, as John Biro and I have argued in articulating our epistemic theory of argument/ argumentation. Cf., for example, J. Biro and H. Siegel, 'Epistemic Normativity, Argumentation, and Fallacies', Argumentation (1997) 11.3: 277-292; J. Biro and H. Siegel, 'Pragma-Dialectic versus Epistemic Theories of Arguing and Arguments: Rivals or Partners?', in P. Houtlosser and A. van Rees, eds., Considering Pragma-Dialectics: A Festshrift for Frans H. van Eemeren on the Occasion of his $60^{\text {th }}$ Birthday, Mahuah, NJ: Erlbaum, 2006, pp. 1-10; H. Siegel and J. Biro, 'Rationality, Reasonableness, and Critical Rationalism: Problems with the Pragma-Dialectical View',

Argumentation (2008) 22.2: 191-203; or H. Siegel, 'Argument Norms: How Contextual Can They Be?', in F. H. van Eemeren and B. Garssen, eds., Reflections on Theoretical Issues in Argumentation Theory, Dordrecht: Springer (in press).

10 Setting aside here difficult cases involving knowledge of necessary truths and the like. 
we do not have reasons, or justification, to reject them merely because they are uncertain." The mere possibility that a belief is false is not a reason to think that it is; neither uncertainty nor possible falsity are themselves justification-defeaters or falsity-indicators. But what is the epistemic status of beliefs enjoying initial credibility: is that status itself a justifier or an indicator of justificatory stature, such that initially credible beliefs enjoy, in virtue of that initial credibility, positive epistemic status? Holma doesn't quite say this, but this is one common and common sense way of understanding Goodman's doctrine. And she seems to understand it this way when she appeals to the initial credibility of the principle of respect for persons as a justifying reason for thinking that "the critical spirit is committed... to the moral value of respect for persons."

The point I'm belaboring is perhaps minor in the scheme of things; I applaud Holma's account of the critical spirit, and we are agreed that the principle of respect for persons enjoys positive epistemic status. My worry here concerns just the justificatory force of initial credibility: I deny that such credibility confers or constitutes positive epistemic status. ${ }^{11}$ Rather than embracing Holma's pragmatic justification of the principle of respect for persons, I favor a Kantian justification in terms of what persons deserve qua persons. But we are agreed both that the principle does enjoy that status, and that, insofar as it does, critical thinkers will embrace it on that basis.

Despite the points of disagreement just rehearsed, Holma and I are very much in agreement on most of her major claims, as already noted. I close this section of the paper by endorsing Holma's defense of critical thinking from the criticisms she attributes to Burbules and Berk and to Fraser. On the first: she is surely right both that while the skills-only view of critical thinking is fairly criticizable for its alleged moral neutrality, the reasons conception and the version of it she defends is not; and that the subordination of critical thinking to the political program of critical pedagogy is untenable. As she well puts it, "It is in the very nature of the ideal of critical thinking that we must be free to think critically about political programs, ideologies, and religious authorities, both those which are dear to us and those which are not."12 On the second, anti-individualist challenge: Holma is surely right that "education always has something to do with individual persons",13 and that while the dangers Fraser points to are real, their avoidance cannot come at the cost of removing individuals from educational theorizing, any more than individual students can be removed from educational practice. Her paper is a welcome contribution to the theory of critical thinking. Especially welcome is her important deepening of our understanding of the critical spirit.

11 This is in fact the biggest philosophical disagreement I had with my mentor Israel Scheffler. Cf. H. Siegel, 'Justification By Balance', Philosophy and Phenomenological Research (1992) 52.1: 27-46.

12 I have argued for this point repeatedly. Among other places, cf. Rationality Redeemed?, Part Two.

13 Cf. E. Robertson, 'The Epistemic Aims of Education', in H. Siegel, ed., The Oxford Handbook of Philosophy of Education (Oxford University Press, 2009), pp. 11-34. 
Ritola's 'Deliberative Democracy, the Deliberating Agent, and Critical Thinking: An Ideal Picture and Some Empirical Challenges' effectively addresses several epistemological matters that have long been at or near the center of my own concerns, and insightfully connects those epistemological concerns with issues in political philosophy generally and deliberative democracy in particular. It is an ambitious paper, treating a large literature and bringing empirical research to bear on fundamental philosophical matters. The paper insightfully brings work in epistemology into fruitful conversation with both empirical research and recent work in political philosophy. Its main thesis is that the importance of the deliberative democratic process, coupled with our (empirically established) difficulty in deliberating effectively, highlights the need for education to foster "not only skills but also dispositions for critical thinking." This jibes well with both Frímannsson's and Holma's discussions; all three authors embrace the reasons conception's understanding of critical thinking as involving both the reason assessment and the critical spirit components of the ideal, and emphasize the educational centrality of the fostering of the dispositions, habits of mind and character traits constitutive of that spirit. I am heartened by this agreement on this fundamental point, and delighted that all three authors contribute importantly to the deepening of my earlier sketchy articulation of it.

Ritola's discussion of deliberative democracy and the importance of the epistemic quality of deliberations - for the democratic decisions reached though such deliberations to be good ones, the reasons on which they are based must genuinely support them, and the reasoning employed must itself be good - is instructive. It highlights the complex interaction among the moral, political and epistemic constraints on deliberation and the difficulties involved in simultaneously honoring them all. It highlights as well the need for citizen deliberators to "have certain inferential or dialectical skills that allow him or her to approximate truth and moral value in deliberation, or reach justified beliefs." Here the deliberative ideal confronts ugly empirical facts: we are, the research shows, lousy reasoners and deliberators; that research "casts serious doubt on our ability as cognitive agents to live up to these requirements." The difficulties are well known: among other problems, our individual reasoning is inferentially flawed, biased in various ways, insufficiently responsive to contrary evidence, and often post-hoc. Our collective reasoning suffers from similar flaws. Ritola reviews the research systematically; I won't repeat the details here. The worry is that these difficulties undermine "the ideal picture of a citizen as an epistemic agent" that deliberative democracy requires.

Ritola's lengthy review of the literature results in a nuanced picture according to which our abilities as reasoners and deliberators are far from perfect, but that educational intervention can help: "We are prone to err in certain ways, but we are able to learn the proper standards of reasoning. However, in order to perform according to these standards, we must also develop and foster attitudes for overcoming these errors. The development of such attitudes, and the consequent improvement in reasoning tasks is not tied to sheer cognitive computing ability." Perhaps surprisingly, it is the development of attitudes and dispositions, rather than improved reasoning skills and abilities, that is crucial to the over- 
coming of our untutored, 'natural' weaknesses as reasoners. Here is a new and welcome reason for emphasizing the fostering of the critical spirit in our educational efforts: not only does it enhance student character, it also improves student reasoning. Ritola notes three further welcome results of doing so. First, "The kinds of skills and dispositions required for epistemically appropriate reasoning bear resemblance to the virtues emphasized in the literature on deliberative democracy." That is, citizens with robust critical spirits (who are competent reason assessors as well) will better approach the ideal of participants in democratic deliberation. Fans of democracy are thus well advised to favor educational efforts to foster both components - especially the critical spirit component - of critical thinking. ${ }^{14}$ Second, these dimensions of the critical spirit also enhance "the quality of one's moral judgment." Third, they can also enhance group reasoning, and help protect such reasoning from predictable defects: as Ritola puts it, "we are not determined to do badly in groups, but we need to have appropriate dispositions for reasoning well in groups." In sum: our reasoning, our moral judgment, our ability to participate in and contribute to high quality democratic deliberation, and our ability to reason well in groups all depend not only on our ability to competently assess reasons, but on our dispositions and characters as well.

Ritola briefly defends two further theses: epistemological internalism and dialectical justification. His discussion of internalism, though brief, is compelling; the connection between this epistemological doctrine and the educational ideal of critical thinking is, as he argues, not necessary, but the two doctrines are nevertheless plausibly linked. As Robertson argues, whatever the case might be concerning the epistemological debate, in education we should be internalists. ${ }^{15}$ Ritola does not defend dialectical justification - the idea, roughly, that a necessary condition of being justified in believing that $p$ is being able to defend $p$ - as a general epistemological doctrine. Rather, he argues that in deliberative contexts, those of interest to proponents of deliberative democracy, "the dialectical condition is just what is needed." He argues that the empirical research he discusses supports both internalism and dialectical justification, though not unequivocally, and that Solomon's arguments to the contrary do not succeed. His arguments here could well be expanded, but they seem to me persuasive. Particularly important is Ritola's discussion of the ways in which epistemological, moral and political constraints on democratic deliberation intersect and interact. As he says, "The epistemologist can...establish that showing and knowing are different things. The political philosopher must instead show how we can manage to decide together despite this difference." His concluding sentence, that "The empirical evidence that we have examined here does not rule out the possibility of reasonable democratic deliberation, given appropriate education of the deliberating agents", should warm the hearts of friends of both rationality and democracy. And his earlier insistence that that 'appropriate education' should emphasize both the reason assessment and especially the

14 As I urged, but with considerably less specificity than Ritola, in Educating Reason, chapter 3.

15 Robertson, 'The Epistemic Aims of Education'. 
critical spirit components of critical thinking should likewise warm the hearts of all those who favor that educational ideal.

The three papers together underline several important features of critical thinking: that the notion of critical thinking is importantly normative, in that episodes of thinking that meet its criteria are episodes of good thinking; that reasons come in many varieties, and the critical thinker must be able to evaluate them in all their many forms and strengths; that the critical thinker's beliefs, judgments and actions are, when appropriately moved by reasons, epistemically justified or warranted; that the critical spirit is an essential component of critical thinking, and that it is fundamentally a matter of character, so that helping students to develop the appropriate character and associated dispositions is an essential part of educating students to be critical; and that education that fosters critical thinking can contribute importantly to democratic deliberation. The papers also importantly deepen our understanding of the ideal, in particular its critical spirit component and its frequently overlooked moral dimensions, and strengthen its justification. I close as I began, by thanking our three authors for their important contributions to the articulation, defense, and further development of this fundamental educational ideal. 